\title{
Cone-beam Computed Tomographic Analysis of Canal Transportation and Centering Ability of Three Different Nickel-Titanium Rotary File Systems
}

Balaji Sopanrao Kapse ${ }^{1 *}$, Pradnya S. Nagmode ${ }^{1}$, Jayshree Ramkrishna Vishwas ${ }^{1}$, Hrishikesh B. Karpe ${ }^{2}$, Harshal V. Basatwar ${ }^{1}$, Shubham P. Godge ${ }^{1}$

${ }^{1}$ Department of Conservative Dentistry and Endodontics, Post Graduate Research Centre, S.M.B.T. Dental College and Hospital, Sangamner, Maharashtra, India; ${ }^{2}$ Department of Pedodontics and Preventive Dentistry, Post Graduate Research Centre, S.M.B.T. Dental College and Hospital, Sangamner, Maharashtra, India

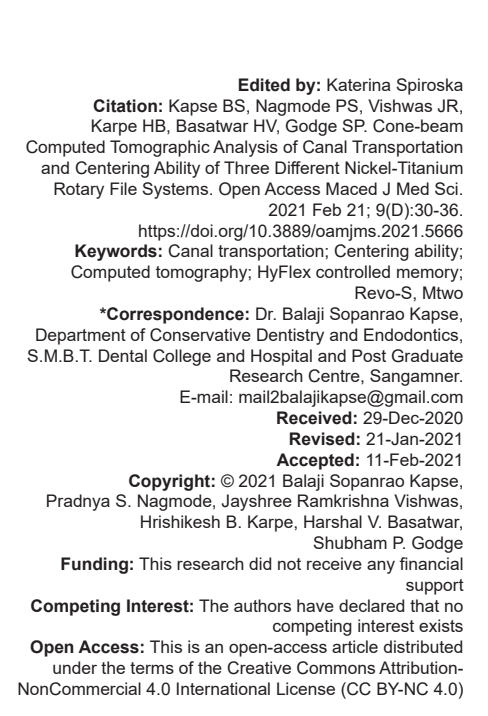

\section{Abstract}

AIM: The aim of the present study was to compare the canal transportation and centering ability of three rotary nickel-titanium file systems, HyFlex controlled memory, Revo-S, and Mtwo in moderately curved root canals using computed tomography (CT).

MATERIALS AND METHODS: Thirty freshly extracted single-rooted teeth having curved root canals with at least $10^{\circ}-20^{\circ}$ of curvature were selected. The teeth were divided into three experimental groups of ten each. After preparation with HyFlex CM (Coltene-Whaledent, Allstetten, Switzerland), Revo-S (Micro-Mega, Besançon, France) and Mtwo (VDW, Munich, Germany) all teeth were scanned using CT to determine the root canal shape. Pre- and post-instrumentation images were obtained at three levels, $3 \mathrm{~mm}$ apical, $9 \mathrm{~mm}$ middle, and $15 \mathrm{~mm}$ coronal above the apical foramen were compared using CT software. Amount of transportation and centering ability were assessed. The three groups were statistically compared with analysis of variance and post-hoc Tukey's honestly significant difference test.

RESULTS: Least apical transportation and higher centering ability were seen in HyFlex CM file system in all the three sections followed by Revo-S, Mtwo file system showed maximum transportation.

CONCLUSIONS: According to the present in-vitro study, we can conclude that HyFlex CM rotary file systems showed least canal transportation and highest centering ability as compared to Revo-S and Mtwo file system but there was no statistically significant difference among these file systems $(p>0.05)$ at coronal, middle, and apical level of root canal.

\section{Introduction}

The primary goal of preparation of the root canal system is to enlarge the root canal space to facilitate the disinfection by antibacterial agents and to prevent reinfection by the placement of a fluid-tight root canal filling followed by complete sealing of the access cavity with a sufficient coronal restoration [1]. The ideal shape of the prepared root canal should have a progressively tapering conical shape which preserves the position of the apical foramen and also maintain the original canal curvature without any transportation [2], [3] and the instruments should remain centered in the root canal throughout the preparation [4], [5], [6]. Canal anatomy varies greatly and studies have reported that root canal curvatures can begin at almost any level [7]. Even canals that are apparently straight may have curvature and irregularities in the apical one-third [8].
There are difficulties in effectively preparing curved and flattened canals because of their complex internal anatomy which is a risk factor for accidents and treatment failure [9]. The results of instrumenting curved root canals are influenced by several factors such as flexibility and diameter of the endodontic instruments, instrumentation techniques, location of the foramen, and hardness of the dentin.

Root canal preparation with nickel-titanium (NiTi) instruments has been a resource which is available to dental professionals since 1988 [10].

According to Thompson [11], the NiTi alloys exhibit super elastic behavior and a shape memory effect. Despite recent advances in the field of endodontic instruments, instrumentation techniques, and devices, instrumentation of curved root canals is difficult and challenging even for skilled and experienced operators. Preparation errors may result during the shaping of these curved root canals such as canal transportation, 
straightening, or canal deviation [12]. As most of the root canals are curved [13], a high prevalence of preparation errors or canal aberrations has been reported in the dental literature [14], [15].

Regardless of the instrumentation technique, cleaning and shaping procedures invariably lead to dentin removal from the canal walls. However, excessive dentin removal in a single direction within the canal rather than in all directions equidistantly from the main tooth axis causes a preparation error known as canal transportation [16]. Deviation from the original canal curvature can cause excessive and inappropriate dentin removal, straightening of the canal and creation of a ledge in the dentinal wall. It also leads to a defect known as an elbow which forms coronal to the elliptical-shaped apical seal, leads to over-preparation of the canal space that weakens the tooth resulting in decreased fracture resistance of the root [17].

The present study investigated the centering ability and canal transportation by three different rotary file systems which are Revo-S files (RS) (MicroMega, Besancon, France) characterized by a unique asymmetrical cross-section that initiates a snakelike movement of the instrument inside the canal [18]. Mtwo $^{\mathrm{TM}}$ (VDW, Munich, Germany) is a newly developed $\mathrm{NiTi}$ rotary file system with $\mathrm{S}$-shaped cross-sectional design, a positive rake angle with 2 cutting edges, no radial lands, progressive blade camber (pitch) in the apical-coronal direction, and a noncutting tip to the shaft. The manufacturer claims that this design prevents threading and binding in continuous rotation and reduces the apical extrusion of debris [19]. HyFlex CM rotary instruments (Coltene-Whaledent, Allstetten, Switzerland) which are made from a new type of NiTi wire, namely CM wire (controlled memory), where it has been subjected to proprietary thermomechanical processing, manufactured by a unique process, that controls the material's memory and makes the files extremely flexible but without the shape memory like other NiTi files [20].

The present study evaluated the ability of three NiTi rotary file systems to maintain the original root canal anatomy using the cone-beam computed tomography (CBCT). Initially several methodologies have been used to evaluate the final shape of root canal preparations such as the serial sectioning technique [21] and optical microscopy [22]. However, when using these methods, there is a loss of part of the specimen structure, as there is a need to cut the tooth before the post-operative evaluation. Radiographic method of evaluation is not destructive but it only allows for two dimensional evaluations of three dimensional root canal systems [23]

CBCT has advantage of increased precision and resolution, as well as reducing the image acquisition time and the time of exposure to radiation. It is non-invasive and permits non-destructive analysis of variables such as volume, surface area, cross-sectional shape, and taper of the root canal system [24].

\section{Materials and Methods}

\section{Specimen selection and preparation}

Access cavities were prepared in thirty extracted human mandibular premolars teeth and a size $10 \mathrm{~K}$-file was inserted through the canals and X-ray was taken, curvature angle was measured following Schneider's technique. Teeth having moderate root curvature ranging from $10^{\circ}$ to $20^{\circ}$ were selected. Glide path was established with size \#15 K file. Standardized $18-\mathrm{mm}$ length was obtained by flattening occlusal surface of all samples.

In the present in-vitro study, three rotary $\mathrm{Ni}-\mathrm{Ti}$ file systems, HyFlex-CM, Revo-S, and Mtwo was used and comparison between canal transportation and centering ability of three rotary file systems. HyFlex CM (Coltene-Whaledent, Allstetten, Switzerland) are continuous rotation rotary instruments, with doublefluted cross-section are made from a new type of $\mathrm{NiTi}$ wire, CM wire. It has been subjected to proprietary thermomechanical processing. It was manufactured by a unique process that controls the material's memory, making the files extremely flexible but without the loss of shape memory typical of other NiTi files. It has Controlled Memory and 300\% more resistant to cyclical fatigue compared to other $\mathrm{NiTi}$ files, which helps reducing the incidence of file separation in the canals.

The design features of Mtwo (VDW, Munich, Germany) instruments have an S-shaped crosssectional design and a non-cutting safety tip. These instruments have a positive rake angle with two cutting edges, which are claimed to cut dentine effectively. Moreover, Mtwo instruments have an increasing pitch length from the tip to the shaft. This design is alleged to have two functions to eliminate threading and binding in continuous rotation and to reduce the transportation of debris toward the apex.

The Revo-S (Micro-Mega, Besançon, France) instruments are characterized by an asymmetrical cross-section with three sharp cutting edges [25]. This design feature is claimed to improve the ability of the instruments to negotiate canal curvatures and to facilitate progression of the instruments toward the apical part of the canal due to a so-called "snake-like" movement of the files [4]. Moreover, it is claimed by the manufacturer that the asymmetrical cross-sectional design decreases the stress on the instrument [26] and avoids the screwing effect.

\section{Canal instrumentation}

The 30 teeth were randomly divided into three experimental groups containing ten teeth each namely.

Before preparation all the teeth were scanned by CBCT (Planmeca ProMax 3D, USA) images was captured in with exposure time was 26.9 s, operating 
at $120 \mathrm{kV}$ and $7 \mathrm{~mA}$ to determine the root canal shape before instrumentation. The sections were taken at $3 \mathrm{~mm}, 9 \mathrm{~mm}$, and $15 \mathrm{~mm}$ from the apex. Then root canals were instrumented using standard techniques.

GROUP I: (HyFlex-CM) (Coltene-Whaledent, Allstetten, Switzerland)

Ten teeth were prepared using HyFlex CM $\mathrm{Ni}-\mathrm{Ti}$ rotary system according to manufacturer's recommendations. The shaping procedure was started with $0.08 / 25$ file as an orifice opener, followed by $0.04 / 25$ file for apical enlargement to the working length (WL). $0.06 / 20$ file was used to shape middle part of the root canal and $0.06 / 25$ file was used to $W L$ to enlarge the apical part of the canal.

France)

GROUP II: (Revo S) (Micro-Mega, Besançon,

Ten teeth were prepared using Revo-S $\mathrm{Ni}-\mathrm{Ti}$ rotary system according to manufacturer's recommendations. The shaping procedure started with $0.06 / 25$ file (SC1) to shape coronal $2 / 3^{\text {rd }}$ of WL, $0.04 / 25$ (SC2) to WL to enlarge apical part of the canal, then final finish with $0.06 / 25$ file (SU) to $\mathrm{WL}$.

\section{GROUP III: (Mtwo) (VDW, Munich, Germany)}

Ten teeth were prepared using Mtwo Ni-Ti rotary system according to manufacturer's recommendations. The instrumentation sequence was as follows: Reliable mechanical instrument sizes $10 / .04$ and $15 / .05$ to WL to enlarge apical part of the canal, then finish with taper 0.06 size 20 , taper 0.06 size 25 .

Teeth were then scanned under the same condition as the initial scan and data were stored.

\section{Evaluation of canal transportation}

The amount of canal transportation was determined by measuring the shortest distance from the edge of an uninstrumented canal to the periphery of the root and then comparing this with the same measurements obtained from the instrumented image [3] (Figure 1a-d). All values were measured and a mean value was taken.

The following formula was used for the calculation of root canal transportation: (a1-a2) - (b1-b2),

where a1 is the shortest distance from the mesial edge of the root to the mesial edge of the un-instrumented canal, b1 is the shortest distance from distal edge of the root to the distal edge of the un-instrumented canal, a2 is the shortest distance from the mesial edge of the root to the mesial edge of the instrumented canal, and b2 is the shortest distance from distal edge of the root to the distal edge of the instrumented canal. According to this formula, a result other than 0 indicates that transportation has occurred in the canal.

\section{Evaluation of centering ability}

The mean centering ratio indicates the ability of the instrument to stay centered in the canal [13]. It was calculated for each section using the following ratio:

$$
(\mathrm{a} 1-\mathrm{a} 2) /(\mathrm{b} 1-\mathrm{b} 2) \text { or }(\mathrm{b} 1-\mathrm{b} 2) /(\mathrm{a} 1-\mathrm{a} 2) \text {, }
$$

If these numbers were not equal, the lower figure was considered as the numerator of the ratio. According to this formula, a result of 1 indicates perfect centering [3].

\section{Statistical analysis}

The mean, standard deviation, minimum, and maximum values were calculated for all the groups in terms of canal transportation and centering ability. One-way analysis of variance (ANOVA) with Tukey's Post hoc; highly significant difference was applied to make multiple inter group pair wise comparison of canal transportation, centering ability among three file system at coronal, middle, and apical section, respectively. All analyses were performed using SPSS windows software version 16.0 and probability $p<0.05$ was considered as statistically significant.

\section{Results}

On comparing three shaping techniques at various sections for canal transportation and centering ability using one-way ANOVA, there were no statistical significant difference among the three file systems at the apical, middle, as well as coronal region $(p>0.05)$ (Tables 1 and 2). Highest centering ability was found in Group I followed by Group III and Group II in coronal section while in Group I followed by Group II and Group III in middle and apical section (Figure 2a-c). Least canal transportation was found in Group I followed by Group III and Group II in coronal and middle section and in Group I followed by Group II and Group III in apical section (Figure 1d-f).

Table 1: Comparison of centering ability among three file systems at apical, middle, and coronal section using ANOVA test

\begin{tabular}{|c|c|c|c|c|c|c|c|}
\hline \multirow[t]{2}{*}{ Group } & \multirow[t]{2}{*}{$\mathrm{n}$} & \multicolumn{2}{|c|}{$3 \mathrm{~mm}$ (apical) } & \multicolumn{2}{|c|}{$9 \mathrm{~mm}$ (middle) } & \multicolumn{2}{|c|}{$15 \mathrm{~mm}$ (coronal) } \\
\hline & & Mean & SD & Mean & SD & Mean & SD \\
\hline $\mathrm{I}$ & 10 & 0.574 & 0.238 & 0.729 & 0.294 & 0.762 & 0.234 \\
\hline II & 10 & 0.532 & 0.341 & 0.595 & 0.136 & 0.540 & 0.218 \\
\hline III & 10 & 0.518 & 0.302 & 0.562 & 0.220 & 0.583 & 0.315 \\
\hline $\mathrm{p}$ (ANOVA) & & $>0.05$ & & $>0.05$ & & $>0.05$ & \\
\hline
\end{tabular}
SD: Standard deviation, ANOVA: Analysis of variance.

\section{Discussion}

Success in root canal treatment depends mostly on how well the root canal system is shaped 
and cleaned. There have been many developments in recent years in this aspect of endodontic practice. The basic principles of root canal preparation remain unchanged. It involves removing of all organic debris and microorganisms from the root canal system and shaping the walls of the root canal to facilitate cleaning and obturation of the root canal space [27].

Table 2: Comparison of canal transportation among three file systems at apical, middle, and coronal section using ANOVA test

\begin{tabular}{|c|c|c|c|c|c|c|c|}
\hline \multirow[t]{2}{*}{ Group } & \multirow[t]{2}{*}{$\mathrm{n}$} & \multicolumn{2}{|c|}{$3 \mathrm{~mm}$ (apical) } & \multicolumn{2}{|c|}{$9 \mathrm{~mm}$ (middle) } & \multicolumn{2}{|c|}{$15 \mathrm{~mm}$ (coronal) } \\
\hline & & Mean & SD & Mean & SD & Mean & SD \\
\hline $\mathrm{I}$ & 10 & 0.060 & 0.037 & 0.052 & 0.051 & 0.057 & 0.087 \\
\hline II & 10 & 0.069 & 0.055 & 0.107 & 0.090 & 0.095 & 0.064 \\
\hline III & 10 & 0.098 & 0.083 & 0.069 & 0.061 & 0.077 & 0.079 \\
\hline \multicolumn{2}{|c|}{$p$ (ANOVA) } & $>0.05$ & & $>0.05$ & & $>0.05$ & \\
\hline
\end{tabular}

The quality guide line of the European Society of Endodontology states that the elimination of residual pulp tissue, the removal of debris, and maintenance of the original canal trajectory during enlargement are the main objectives of root canal instrumentation [28].

During instrumentation root canal should develop a shape that tapers from coronal to the apical while maintaining the original canal shape [3] cleaning and shaping the canal space will allow adequate chemical debridement. Regardless of the instrumentation technique, cleaning and shaping procedures invariably lead to dentine removal from the canal walls [29]. However, excessive dentine removal in a single direction within the canal rather than in all directions equidistantly from the main tooth axis causes "canal transportation [30]." There are various factors which are associated with an increased risk of canal transportation; it includes insufficiently designed access cavities, use of inflexible instruments, instrumentation technique, insufficient irrigation during mechanical canal enlargement, degree and radius of a canal curvature, unseen canal curvatures in two dimensional radiographs, and experience of the operator.

As a result of this asymmetrical dentin removal during shaping, the long axis of the curved root canal will be displaced and the angle of curvature will decrease, resulting in straightening of the original curvature of the root canal.

Independent of the alloy used, any root canal instrument tends to straighten itself inside the root canal system. Due to the restoring forces, an uneven force distribution of the cutting edges of the instrument in certain contact areas along the root canal wall results in asymmetrical dentin removal. In particular, the cutting edges are pressed against the outer side of the curved canal (convexity) in the apical third and against the inner side at the middle or coronal thirds (concavity). As a result, apical canal areas tend to be over prepared toward the convexity of the canal, whereas coronally greater amounts of dentin will be removed at the concavity, leading to canal transportation or straightening of varying degrees [31]. The undesirable canal preparation can cause damage to the apical foramen, zip formation, elbow formation, perforation, strip perforation, or ledging.

The ability to keep the instruments centered is essential to provide a correct enlargement without excessive weakening of the root canal structure. Considerable research has been undertaken by $\mathrm{El}$ Batouty and Fekry [18], Zhao et al. [20], Short et al. [32], Sánchez et al. [33], and Vallaeys et al. [34] to understand the factors related to an instrument's canal centering ability. Centering ability is the capability of the instrument to stay centered in the canal [3]. If the instrument fails to remain centered in the curved canal, it could result in irregularly shaped canals. Hence, multiple plane preparation both in buccolingual and mesiodistal direction is necessary when dealing with such curved root canals to preserve the natural curve of flow [35].

Several factors were considered for the choice of the instruments used in this study to make them different from other systems such as manufacturing processes and different cutting profiles. In the present in-vitro study, three rotary $\mathrm{Ni}-\mathrm{Ti}$ systems, HyFlex-CM, Revo-S, and Mtwo were used and comparison between canal transportation and centering ability of three rotary file systems. It has been subjected to proprietary thermomechanical processing. It was manufactured by a unique process that controls the material's memory, making the files extremely flexible but without the loss of shape memory typical of other NiTi files. It has controlled memory and $300 \%$ more resistant to cyclical fatigue compared to other NiTi files, which helps reducing the incidence of file separation in the canals.

The design features of Mtwo instruments have an S-shaped cross-sectional design and a noncutting safety tip. These instruments have a positive rake angle with two cutting edges, which are claimed to cut dentine effectively. Moreover, Mtwo instruments have an increasing pitch length from the tip to the shaft. This design is alleged to have two functions to eliminate threading and binding in continuous rotation and to reduce the transportation of debris toward the apex.

The efficacy of Mtwo rotary systems has been compared to that of other rotary files. Foschi et al. [36] reported that both the Mtwo and Protaper rotary systems produced a clean canal in the coronal and middle thirds, but were unable to produce dentine surfaces free from smear layer and debris in the apical third. Schafer and Oitzinger [37] found that Mtwo and Race instruments had a greater cutting efficiency than Profile, FlexMaster, and Alfa-file rotary NiTi instruments.

The Revo-S instruments (Micro Mega, Besancon, France)are characterized by an asymmetrical cross-section with three sharp cutting edges [25]. This design feature is claimed to improve the ability of the instruments to negotiate canal curvatures and to facilitate progression of the instruments toward the apical part of the canal due to a so-called "snake-like" 
movement of the files [4]. Moreover, it is claimed by the manufacturer that the asymmetrical cross-sectional design decreases the stress on the instrument [26] and avoids the screwing effect.

Recently, cone-beam CT has been adapted for dentistry and compared with medical tomography that leads to increased precision and resolution, as

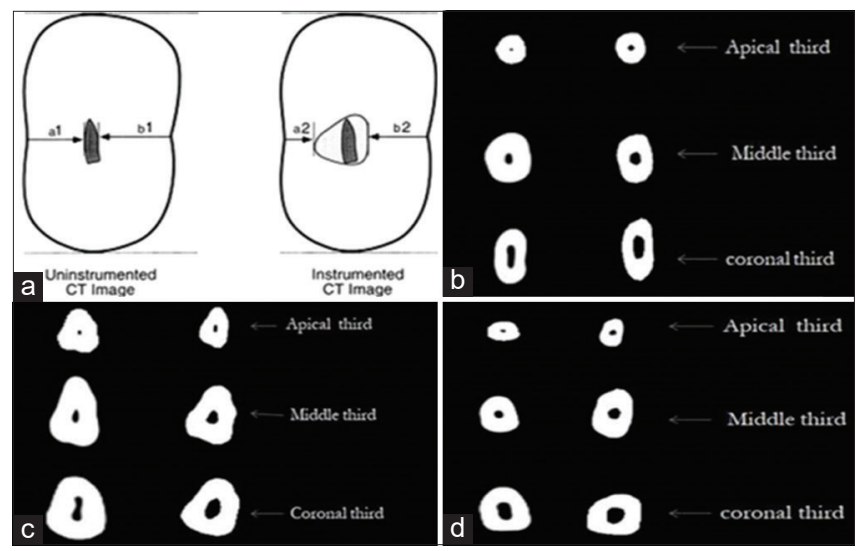

Figure 1: (a) Diagrammatic representation of cone-beam computed tomography (CBCT) images for measurement of centering ability and canal transportation. (b) Pre- and post-instrumentation CBCT images of Group I- HyFlex-CM rotary file system. (c) Pre- and postinstrumentation CBCT images of Group II Revo-S rotary file system (d) Pre- and post-instrumentation CBCT images of Group III- Mtwo rotary file system well as reducing the image acquisition time and the time of exposure to radiation [24] Gundappa et al. [38] revealed that $\mathrm{CBCT}$ provides a highly precise threedimensional non-invasive tool for the evaluation of changes in canal geometry following instrumentation. It permits non-destructive analysis of variables such as volume, surface area, cross-sectional shape, and taper of the root canal system.

CBCT enabled the calculation of canal transportation and centering abilities of the endodontic systems. Other advantages are three-dimensional rendition, geometrically precise images, increased sensitivity and specificity for caries, periodontal and periapical lesions, patient comfort, no intra-oral placement of film or sensor, and soft tissue interpretation. In the present study, we used CBCT, which provided a practical and non-destructive technique for assessment of canal morphology before and after shaping according to Gluskin et al. [39]

Three levels (i.e., 15, 8, and $3 \mathrm{~mm}$ from the root apex) were chosen representing the coronal, middle, and apical thirds of root canal, in which curvatures are usually seen and are highly susceptible to iatrogenic mishaps [4].

In present study, HyFlex CM files showed the highest amount of canal centering ability and least canal transportation at coronal, middle, and apical sections.

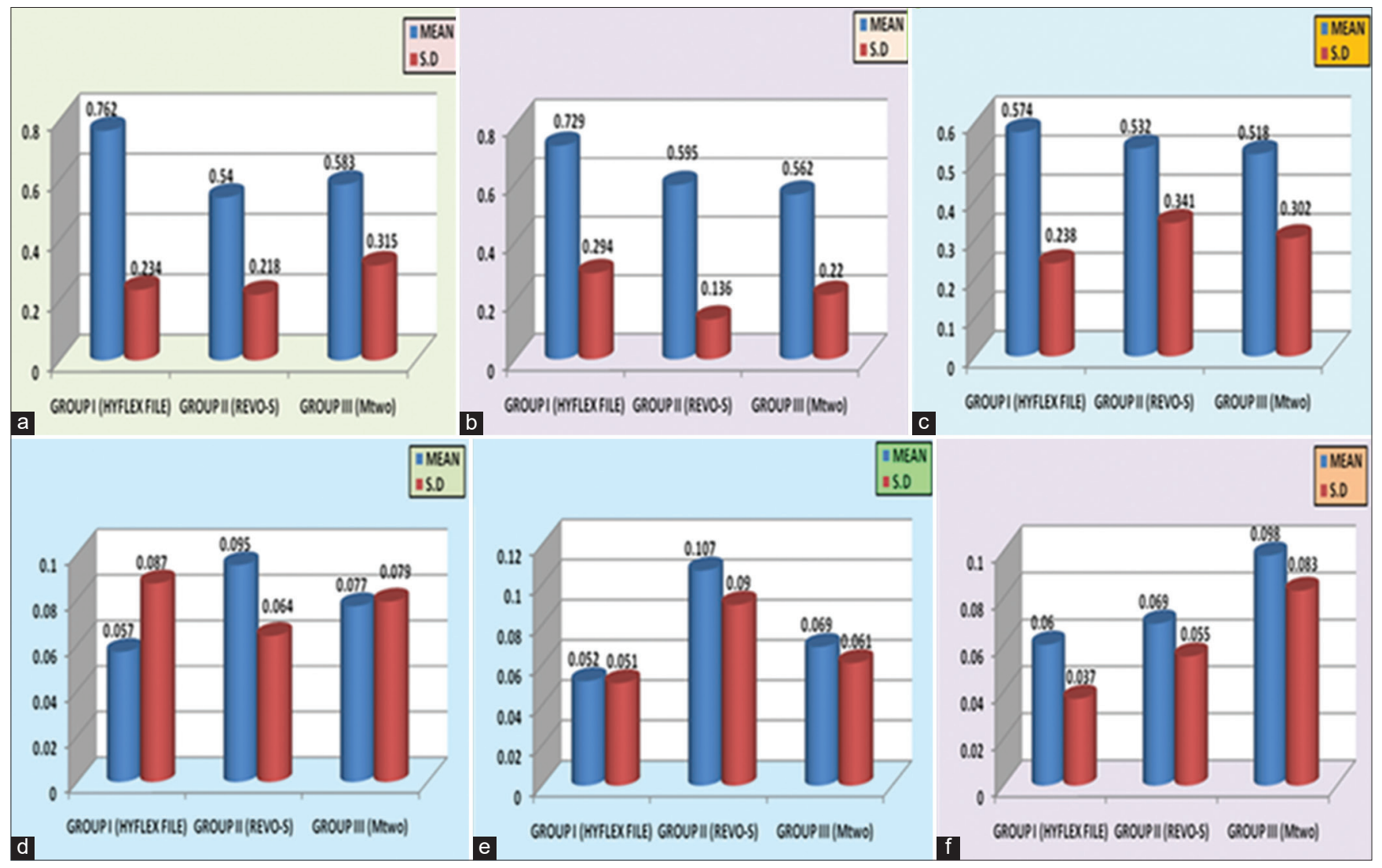

Figure 2: (a) Comparison of centering ability among three groups at coronal section. (b) Comparison of centering ability among three groups at middle section. (c) Comparison of centering ability among three groups at apical section. (d) Comparison of canal transportation among three groups at coronal section. (e) Comparison of canal transportation among three groups at middle section. (f) Comparison of canal transportation among three groups at apical section 
The present findings are in accordance with the study Kishore et al. [40], where it was seen that in the coronal and the middle thirds of the canals, HyFlex CM files caused slightly less transportation and more centered preparation. The present study showed that HyFlex CM files maintained the original canal curvature well and is corroborated by recent studies conducted under similar experimental conditions and using microcomputed tomography evaluation [20]. The good shaping ability can be attributed to the increased flexibility of these instruments. HyFlex $\mathrm{CM}$ files have been reported to be significantly more flexible than ProFile, Hero 642, FlexMaster (VDW, Munich, Germany), and EndoSequence instruments [41] and less stiff than Profile Vortex and RaCe [42].

To conclude present in-vitro study was undertaken to compare canal transportation and centering ability of HyFlex CM, Revo-S, and Mtwo rotary file systems in moderately curved canals. The HyFlex CM rotary file systems showed least canal transportation and highest centering ability as compared to Revo-S and Mtwo. Revo-S showed the highest amount of canal centering ability at middle and apical section, least amount of canal transportation at apical section as compared to Mtwo rotary file system. Mtwo file system represented with highest amount of canal transportation and least centering ability at apical sections and there was no statistically significant difference in between these file systems $(p>0.05)$ at all three levels which are coronal, middle, and apical.

\section{Conclusions}

According to the results of the present investigation and within the limitations of this in-vitro study, we can conclude that HyFlex CM rotary file systems showed least canal transportation and highest centering ability as compared to Revo-S and Mtwo file system but there was no statistically significant difference among these file systems $(p>0.05)$ at coronal, middle, and apical level of root canal.

\section{References}

1. Schafer E, Dammaschke T. Development and sequelae of canal transportation. Endod Top. 2009;15:75-90.

2. Garip Y, Gunday M. The use of computed tomography when comparing nickel-titanium and stainless steel files during preparation ofsimulatedcurvedcanals. IntEndodJ.2001;34(6):4527. https://doi.org/10.1046/j.1365-2591.2001.00416.x PMid:11556512

3. Schilder $\mathrm{H}$. Cleaning and shaping the root canal. Dent Clin North Am. 1974;18(2):269-96.

\section{PMid:4522570}

4. Aguiar CM, Fernanda A, Câmara AC, Frazão M. Cone beam computed tomography: A tool to evaluate root canal preparations. Actastomatolcroat. 2012;46(4):273-9.

5. Elayouti A, Dima E, Judenhofer MS, Lost C, Pichler BJ. Increased apical enlargement contributes to excessive dentin removal in curved root canals: A stepwise microcomputed tomography study. J Endod. 2011;37(11):1580-4. https://doi. org/10.1016/j.joen.2011.08.019

\section{PMid:22000468}

6. Camara AC, Aguiar CM, Poli de Figueiredo JA. Assessment of the deviation after biomechanical preparation of the coronal, middle, and apical thirds of root canals instrumented with three HERO rotary systems. J Endod. 2007;33(12):1460-3. https:// doi.org/10.1016/j.joen.2007.07.029

PMid:18037059

7. Wildey WL, Senia ES, Montgomery S. Another look at root canal instrumentation. Oral Surg Oral Med Oral Pathol. 1992;74(4):499507. https://doi.org/10.1016/0030-4220(92)90303-8

PMid: 1408028

8. Skidmore AE, Bjorndal AM. Root canal morphology of the human mandibular first molar. Oral Surg Oral Med Oral Pathol. 1971;32(5):778-84. https://doi. org/10.1016/0030-4220(71)90304-5

PMid:5286234

9. Meireles D, Marques AF, Garcia LF, Garrido AD, Sponchiado EC Assessment of apical deviation of root canals after debridement with the hybrid, protaper and pathfile systems. J Int Dent. 2012;2(1):20-4. https://doi.org/10.4103/2229-5194.94187

10. Pasternak-Junior B, Sousa-Neto MD, Silva RG. Cana transportation and centring ability of RaCe rotary instruments. Int Endod J. 2009;42(6):499-506. https://doi. org/10.1111/j.1365-2591.2008.01536.x

PMid: 19298575

11. Thompson SA. An overview of nickel-titanium alloys used in dentistry. Int Endod J. 2000;33(4):297-310. https://doi. org/10.1046/j.1365-2591.2000.00339.x

PMid:11307203

12. Weine FS, Kelly RF, Lio PJ. The effect of preparation procedures on original canal shape and on apical foramen shape. J Endod. 1975;1(8):255-62. https://doi.org/10.1016/ s0099-2399(75)80037-9

PMid:10697472

13. Schafer E, Diez C, Hoppe W, Tepel J. Roentgenographic investigation of frequency and degree of canal curvatures in human permanent teeth. J Endod. 2002;28(3):211-6. https://doi. org/10.1097/00004770-200203000-00017

PMid:12017184

14. Peters OA. Current challenges and concepts in the preparation of root canal systems: A review. J Endod. 2004;30(8):559-67. PMid:15273636

15. Hulsmann M, Peters OA, Dummer PM. Mechanical preparation of root canals: Shaping goals, techniques and means. Endod Top. 2005;10:30-76. https://doi. org/10.1111/j.1601-1546.2005.00152.x

16. Hartmann MS, Barletta FB, Fontanella VR, Vanni JR. Canal transportation after root canal instrumentation: A comparative study with computed tomography. J Endod 2007;33(8):962-5. https://doi.org/10.1016/j.joen.2007.03.019

PMid:17878083

17. Kandaswamy D, Venkateshbabu N, Porkodi I, Pradeep G. Canal-centering ability: An endodontic challenge. J Conserv Dent. 2009;2(1):39. https://doi.org/10.4103/0972-0707.53334 PMid:20379433 
18. El Batouty KM, Fekry WW. Canal centering ability of M two, Twisted Files and Revo-S nickel-titanium rotary instruments. ENDO (Lond Engl). 2012;(2):125-30.

19. Carlos MA, Fernanda AD, Andréa C, Marco F. Changes in root canal anatomy using three nickel-titanium rotary system a cone beam computed tomography. Braz J Oral Sci. 2013;12(4):30712. https://doi.org/10.1590/s1677-32252013000400006

20. Zhao D, Shen Y, Peng B, Haapasalo M. Micro-computed tomography evaluation of the preparation of mesiobuccal root canals in maxillary first molars with Hyflex $\mathrm{CM}$, twisted files, and k3 instruments. J Endod. 2013;39(3):385-8. https://doi. org/10.1016/j.joen.2012.11.030

PMid:23402512

21. Bramante CM, Berbert A, Borges RP. A methodology for evaluation of root canal instrumentation. J Endod. 1987;13:5:2435. https://doi.org/10.1016/s0099-2399(87)80099-7

PMid:3473181

22. Jung IY, Seo MA, Fouad AF, Spangberg LS, Lee SJ, Kim HJ, et al. Apical anatomy in mesial and mesiobuccal roots of permanent first molars. J Endod. 2005;31(5)364-8. https://doi. org/10.1097/01.don.0000145425.73364.91

PMid: 15851930

23. Sydney GB, Batista A, de Melo LL. The radiographic platform: A new method to evaluate root canal preparation in vitro. J Endod. 1991;17(11):570-2. https://doi.org/10.1016/ s0099-2399(06)81724-3

PMid:1812207

24. Arnheiter C, Scarfe WC, Farman AG. Trends in maxillofacial cone-beam computed tomography usage. Oral Radiol. 2006;22:80-5. https://doi.org/10.1007/s11282-006-0055-6

25. Hashem AA, Ghoneim AG, Lutfy RA, Foda MY, Omar GA Geometric analysis of root canals prepared by four rotary NiTi shaping systems. J Endod. 2012;38(7):996-1000. https://doi. org/10.1016/j.joen.2012.03.018

PMid:22703669

26. Basrani B, Roth K, Sas G, Kishen A, Peters OA. Torsional profiles of new and used Revo-S rotary instruments: An in vitro study. J Endod. 201137(7):989-92. https://doi.org/10.1016/j. joen.2011.03.029

PMid:21689557

27. Oliveira CA, Meurer MI, Pascoalato C, Silva SR. Cone-beam computed tomography analysis of the apical third of curved roots after mechanical preparation with different automated systems. Braz Dent J. 2009;20(5):376-81. https://doi.org/10.1590/ s0103-64402009000500004

PMid:20126905

28. European Society of Endodontology. Consensus report of the European Society of Endodontology on quality guidelines for endodontic treatment. Int Endod J. 1994;27(3):115-24. https:// doi.org/10.1111/j.1365-2591.1994.tb00240.x PMid:7995643

29. Yun HH, Kim SK. A comparison of the shaping abilities of 4 nickel-titanium rotary instruments in simulated root canals. Oral Surg Oral Med Oral Pathol Oral Radiol Endod. 2003;95(2):22833. https://doi.org/10.1067/moe.2003.92 PMid:12582365

30. Iqbal MK, Firic S, Tulcan J, Karabucak B, Kim S. Comparison of apical transportation between ProFile and ProTaper NiTi rotary instruments. Int Endod J. 2004;37(6):359-64. https://doi. org/10.1111/j.1365-2591.2004.00792.x PMid:15186241

31. Al-Sudani D, Al-Shahrani S. A comparison of the canal centering ability of ProFile, K3, and RaCe Nickel Titanium rotary systems. J Endod. 2006;32(12):1198-201. https://doi.org/10.1016/j. joen.2006.07.017

PMid:17174683.

32. Short JA, Morgan LA, Baumgartner JC. A comparison of canal centering ability of four instrumentation techniques. J Endod. 1997;23(8):503-7. https://doi.org/10.1016/ s0099-2399(97)80310-x

PMid:9587320

33. Sánchez JA, Duran-Sindreu $F$, de Noé $S$, Mercadé $M$, Roig M. Centring ability and apical transportation after over instrumentation with ProTaper Universal and ProFile Vortex instruments. Int Endod J. 2012;45(6):542-51. https://doi. org/10.1111/j.1365-2591.2011.02008.x PMid:22264187

34. Vallaeys K, Chevalier V, Arbab-Chirani R. Comparative analysis of canal transportation and centring ability of three $\mathrm{Ni}-\mathrm{Ti}$ rotary endodontic systems: Protaper $^{\circledR}$, MTwo $^{\circledR}$ and Revo- $\mathrm{S}^{\mathrm{TM}}$, assessed by micro-computed tomography. Odontology. 2016;104(1):83-8. https://doi.org/10.1007/s10266-014-0176-z

\section{PMid:25248755}

35. Nagaraja S, Murthy BS. CT evaluation of canal preparation using rotary and hand $\mathrm{NI}-\mathrm{Tl}$ instruments: An in vitro study. J Conser Dent. 2010;13(1):16-22 https://doi.org/10.4103/0972-0707.62636.

PMid:20582214

36. Foschi F, Nucci C, Montebugnoli L, Marchionni S, Breschi L, Malagnino VA, et al. SEM evaluation of canal wall dentine following use of Mtwo and ProTaper NiTi rotary instruments. Int Endod J. 2004;37(12):832-9. https://doi. org/10.1111/j.1365-2591.2004.00887.x

PMid: 15548274

37. Schafer E, Oitzinger M. Cutting efficiency of five different types of rotary nickel-titanium instruments. J Endod. 2008;34(2):198200. https://doi.org/10.1016/j.joen.2007.10.009

PMid:18215681

38. Gundappa M, Bansal R, Khoriya S, Mohan R. Root canal centering ability of rotary cutting nickel titanium instruments: A meta-analysis. J Conserv Dent. 2014;17(6):504. https://doi. org/10.4103/0972-0707.144567 PMid:25506134

39. Gluskin AH, Brown DC, Buchanan LS. A reconstructed computerized tomographic comparison of $\mathrm{Ni}-\mathrm{Ti}$ rotary $\mathrm{GT}^{\mathrm{TM}}$ files versus traditional instruments in canals shaped by novice operators. Int Endod J. 2001;34(6):476-84. https://doi. org/10.1046/j.1365-2591.2001.00422.x

PMid:11556516

40. Kishore A, Gurtu A, Bansal R, Singhal A, Mohan S, Mehrotra A. Comparison of canal transportation and centering ability of twisted files, hyflex controlled memory, and wave one using computed tomography scan: An in vitro study. J Conser Dent. 2017;20(3):161-5. https://doi.org/10.4103/jcd.jcd_110_16 PMid:29279618

41. Testarelli L, Plotino G, Al-Sudani D, Vincenzi V, Giansiracusa A, Grande NM, et al. Bending properties of a new nickel-titanium alloy with a lower percent by weight of nickel. J Endod. 2011;37(9):1293-5. https://doi.org/10.1016/j.joen.2011.05.023 PMid:21846552

42. Pongione G, Pompa G, Milana V, Di Carlo S, Giansiracusa A, Nicolini $\mathrm{E}$, et al. Flexibility and resistance to cyclic fatigue of endodontic instruments made with different nickeltitanium alloys: A comparative test. Ann Stomatol (Roma) 2012;3:11922. PMid:23386933 